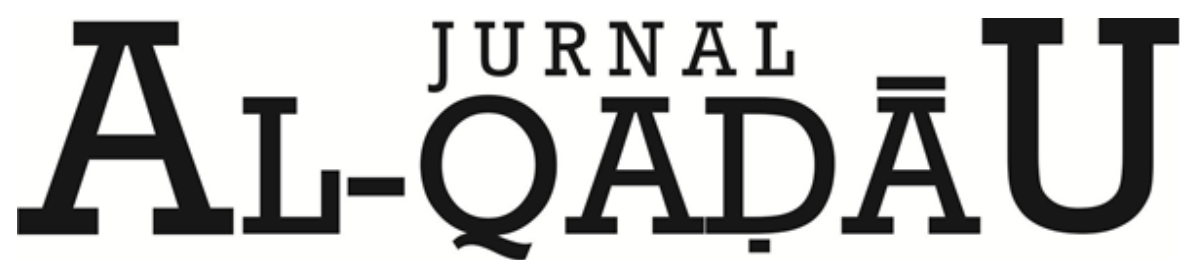

PERADILAN dan HUKUM KELUARGA ISLAM

\section{Eksistensi Aurat Wanita dalam Fiqih}

The Existence of Women's Aurat in Fiqh

Masri

Dosen Universitas Islam Makassar

Email:_masri_saad@yahoo.co.id

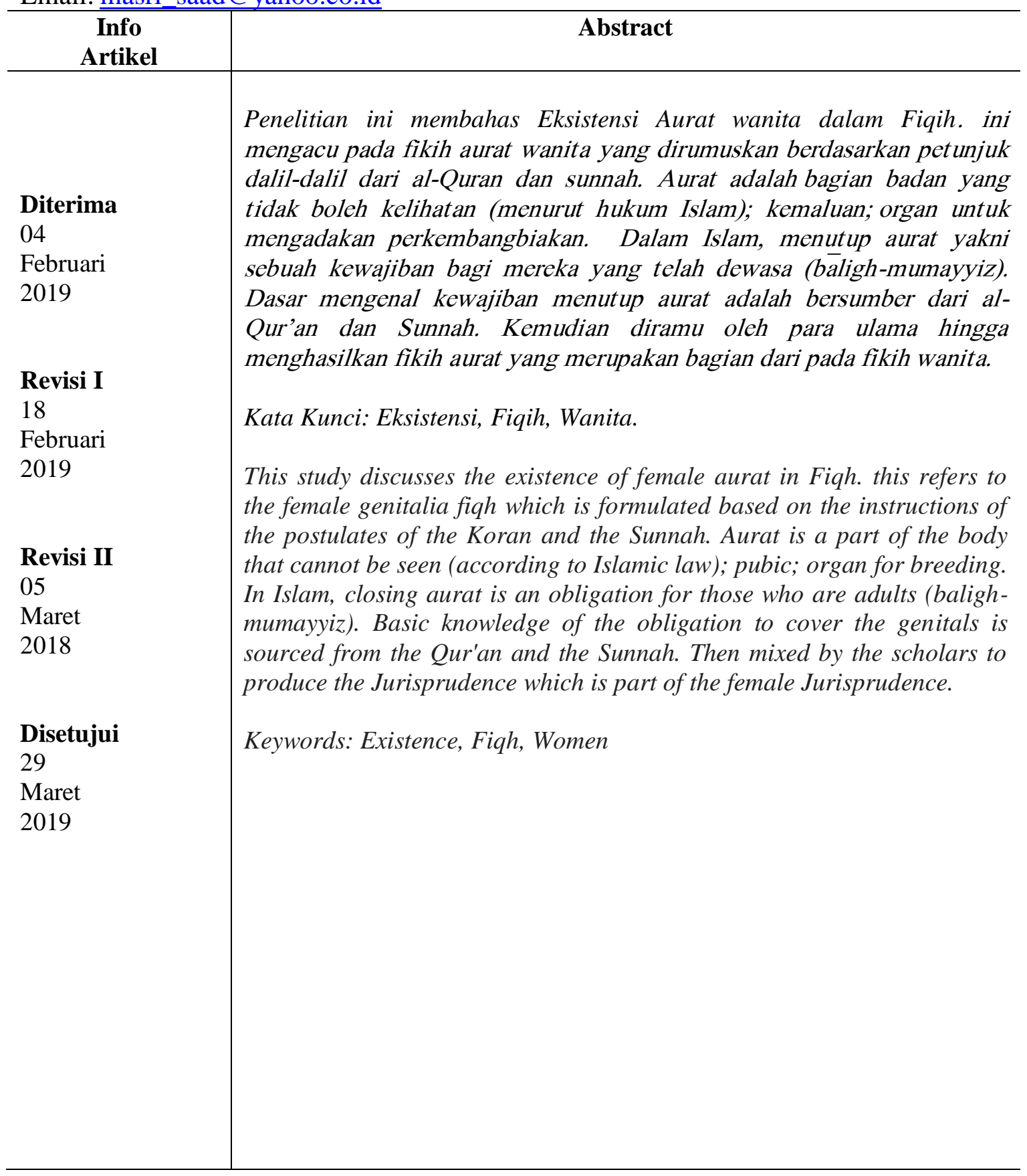


Masri

\section{A. PENDAHULUAN}

Ajaran Islam Islam yang mengatur tata cara hidup disebutal-hukm (hukum), dimana wadah yang menampung tatacara hidup tersebut disebut al-fiqh yang kemudian diindonesiakan menjadi fikih. ${ }^{1}$ Fikih adalah pola hidup umat Islam. Termasuk di dalamnya adalah fikih aurat. Kajian seputar aurat ternyata tidak berhenti pada fikih yang telah dirumuskan oleh para fuqaha dan ulama. Banyak cendekiawan yang berusaha menggali kembali defenisi aurat yang selama ini dipahami oleh sebagian besar umat Islam tentang batas anggota tubuh yang boleh terlihat dan tidak boleh terlihat. Tentu di sini, persoalan aurat menggiring banyak persoalan di kemudian, semisal hijab yang terdiri dari jilb $\bar{a} b$, khimar, dir säbigh, milhä, dan sebagainya. Mereka mempertanyakan kembali letak dalil Tuhan tentang aurat. ${ }^{2}$

Fikih telah menjelaskan batasan aurat pria maupun wanita, baik di dalam soal ibadah seperti shalat dan ihram, maupun di dalam atau di luar rumah. ${ }^{3}$ Batasan yang sangat jelas (bayyin) ini ternyata tidak dianggap final. Para feminis muslim seperti Fatima Mernissi menganggap aurat itu bukan terletak pada cakrawala budaya. Seperti jilbāb bukanlah budaya Arab, melainkan budaya ajam yang diarabkan. ${ }^{4}$ Jika daerah Afrika, Papua, dan penghuni pedalaman memakai pakaian yang hanya menutup kelamin saja, maka menurut feminis muslim adalah batasan aurat mereka adalah sebatas kelamin saja yaitu penis dan vagina.

Paha bukanlah aurat bagi laki-laki dan payudara bukan pula aurat bagi perempuan di sana. Jika eksistensi batasan aurat di Timur Tengah ingin diterapkan di daerah Afrika, Papua, dan pedalaman, maka itu adalah pemaksaan budaya yang keliru. Aurat dalam pandangan feminis muslim adalah yang jika diperlihatkan tidak membuat risih dan jika dilihat tidak pula membuat risih. Maka fenomena bikini di Bali bukanlah fenomena menampakkan aurat, melainkan fenomena sudah menutup aurat karena orang-orang di sana tidak risih dengan pakaian bikini. ${ }^{5}$ Padahal, menurut Umar Syihab, masyarakat itu membutuhkan wahyu yang bertujuan untuk mengubah prilaku aljahiliyyah menuju al-madaniyyah yang disampaiakan lewat dakwah yang argumentatif (al-'aqliyyah) dan bijaksana (al-hikmah). ${ }^{6}$ Maka peradaban yang jahiliyyah membutuhkan asupan dakwah agar berubah dari buruk menuju baik. Dan peradaban membuka aurat adalah bagian dari hidup jahiliyyah yang membutuhkan asupan

${ }^{1}$ Ahmad Azhar Basyir, Refleksi atas Persoalan Keimanan (Seputar Masalah Filsafat, Hukum, Politik dan Ekonomi), (Bandung: Mizan, 1996), h. 128.

${ }^{2}$ Zuly Qadir, Islam Liberal: Varian-Varian Liberalisme Islam di Indonesia 1991-2002. (Yogyakarta: LkiS, 2002), h. 220-241.

${ }^{3}$ Menurut Muhammad Mutawalli Sya'rawi, para ulama sepakat bahwa seluruh tubuh wanita adalah aurat, kecuali wajah dan telapak tangannya. Abū Hanifah menambah pengecualian itu dengan kedua kaki hingga mata kaki. Lih. Muhammad Mutawalli Sya' $\overline{r a w i}$, Fiqih Wanita, (terj.) Ghozi. M, dari judul Fiqh al-Mar'ah al-Muslimah, (Jakarta: Pena Pundi Aksara, 2006), h. 50.

4 "Penafsiran Ulang Ayat-Ayat Tentang Perempuan" dalam Said Agil Husin Al Munawar, AlQuran: Membangun Tradisi Keshalehan Hakiki. (Jakarta: Ciputat Press, 2003), h. 214.

${ }^{5}$ Tentang kondisi sosial adalah bagian dari budaya yang dirangkul oleh syariat. Maka jelas jika syariat itu menurut feminis muslim sesuai dengan kadar budaya setempat. Lih. Zuly Qadir, Islam Liberal: Varian-Varian Liberalisme Islam di Indonesia 1991-2002. (Yogyakarta: LkiS, 2002), h. 171.

${ }^{6}$ Umar Shihab, Kontektualitas Al-Quran: Kajian Tematik Atas Ayat-Ayat Hukum Dalam Al Qur'an. (Jakarta: Penamadani, 2005), h. 23. 
madāniyyah. Berdasarkan latar belakang di atas, maka persoalan yang menjadi kajian utama dalam penelitian ini yaitu bagaimana Eksistensi aurat wanita dalam fiqih.

\section{B. METODE PENELITIAN}

Penelitian ini adalah tipe penelitian kepustakaan atau library research. Penelitian ini mengumpulkan data-data pustaka yang bertalian dengan fikih yang universal, fikih wanita klasik dan sebagainya. Dalam menganalisis data, metode yang digunakan adalah kualitatif dengan menggunakan teknik analisis isi. ${ }^{7}$

\section{PEMBAHASAN}

\section{Pengertian Aurat.}

Aurat menurut Kamus Besar Bahasa Indonesia (KBBI) adalah bagian badan yang tidak boleh kelihatan (menurut hukum Islam); kemaluan; organ untuk mengadakan perkembangbiakan. ${ }^{8}$ Pengertian aurat secara etimologi berarti yang kekurangan, atau dalam Bahasa Arab disebut dengan al-nuqsan. ${ }^{9}$

Ada pula yang mengartikan dengan sesuatu yang dihinakan untuk dilihat walaupun dari jin dan malaikat. Aurat dinamakan kepada tempat-tempat yang akan kita bahas, karena hina memperlihatkannya. ${ }^{10}$ Sedangkan pengertian aurat menurut terminologi (istilah fikih) yaitu sesuatu yang wajib ditutup dalam shalat. Oleh para ulama, sering kepada aurat juga mendefinisikannya dengan sesuatu yang haram dilihat. ${ }^{11}$

Dalam Lisān al-'Arab, disebutkan, “Kull 'aib wa khalal fí syai' fahuwa 'aurah (setiap aib dan cacat cela pada sesuatu disebut dengan aurat). Wa syai mu'wirun au 'awirun: là hăfiza lahū (sesuatu itu tidak memiliki penjaga). '’2

\section{Aurat dalam Pandangan Islam.}

Islam sangat menghargai manusia. Maka dari itu, Islam mengatur tata cara manusia hidup, mulai dari hal mikro hingga makro. Termasuk tata cara berpakaian. Untuk mengenal bagaimana Islam mengatur tata cara berpakaian, tentu diawali bagaimana Islam mengatur batasan-batasan aurat.

${ }^{7}$ Content analysis adalah suatu teknik penelitian untuk membuat inferensi-inferensi yang dapat ditiru (replecabel). Lihat Klaus Krippendorf, Content Analysis, Introduction to it'sTheory and Methodology. Terj. Farid Wadji dengan judul Analisis Isi, Pengantar Teori dan Methodology, (Jakarta: Rajawali Press, 1991), h. 15. Content Analysis juga dikenal dengan analisis dokumen, analisis aktifitas dokumen, dan analisis informasi. Penjelasan selanjutnya lihat Suharsimi Arikunto, Prosedur Penelitian: Suatu Pendekatan Praktek (Jakarta: Rineka Cipta, 1998), h. 92.

${ }^{8}$ Tim Penyusun Kamus Pusat Pembinaan dan Pengembangan Bahasa Departemen Pendidikan dan Kebudayaan, Kamus Besar Bahasa Indonesia, h. 87

${ }^{9}$ Menurut pengertian yang lebih, aurat adalah al-nuqsāan wa al-syai' al-mustaqabbih (kekurangan dan sesuatu yang mendatangkan celaan). Diantara bentuk pecahan katanya adalah 'awara, yang bermakna qabīh (tercela); yakni aurat manusia dan semua yang bisa menyebabkan rasa malu. Disebut aurat, karena tercela bila terlihat (ditampakkan). Lih. Muhammad al-Khatib Al-Syarbini, Mughnī al-Muhtaj, Juz I, (Mesir: Mathba'ah al-Istiqamah, 1374 H/1955 M), h. 256.

${ }^{10}$ Syihāab al-Dīn Ahmad bin Aḥmad bin Salamah Qalyūbi dan Syihāb al-Dīn Ahmad al-Barlasī Umairah, Hasyiyàtāni Qalyūbi wa Amïrah, jilid III (Beirut: Där al-Fikr, 1995), h 200.

${ }^{11}$ Muhammad al-Khatīb Al-Syarbini, Mughnī al-Muhtajj, Juz I, h. 256

${ }^{12} \mathrm{Abu}$ al-Fadl Jamal al-Din Muhammad Ibn Makram Ibn Manẓūr, Lisān al-'Arab, jilid 4 (Beirut: Där Sad, t.th.), h. 616. 
Masri

\section{Eksistensi Kajian Aurat Wanita dalam Fikih dan Tafsir.}

Makna jilbāb dalam pandangan al-Qur'an. Secara bahasa, kata al-jilbāb sama dengan kata al-qamiș atau baju kurung yang bermakna baju yang menutupi seluruh tubuh. Ia juga sama dengan al-khimar atau tudung kepala yang bisa dimaknai dengan apa yang dipakai di atas baju seperti selimut dan kain yang menutupi seluruh tubuh wanita. ${ }^{13}$

Jilbāb berasal dari kata kerja jalaba yang berarti menutupkan sesuatu di atas sesuatu yang lain sehingga tidak dapat dilihat. Dalam masyarakat Islam selanjutnya, jilba $\bar{a}$ diartikan sebagai pakaian yang menutupi tubuh seseorang. Bukan hanya kulit tubuhnya tertutup, melainkan juga lekuk dan bentuk tubuhnya tidak kelihatan. ${ }^{14}$

Penelusuran atas teks al-Qur'an tentang jilbäb agaknya tidak sama dengan pengertian sosiologis tersebut. Para ahli tafsir menggambarkan jilba $\bar{a}$ dengan cara yang berbeda-beda. Muhammad bin Sirin berkata, "Aku bertanya kepada Abidah As-

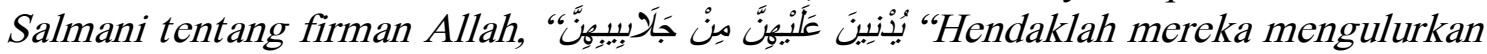
jilbabnya ke seluruh tubuh mereka " maka ia menutup wajah dan kepalanya, serta hanya memperlihatkan mata kirinya. ${ }^{15}$ Pendapat ini tidak familiar karena tidak ada nas yang menguatkan.

Para ahli tafsir berbeda pendapat dalam masalah mengulurkan jilb $\bar{a} b$ yang dimaksudkan Allah dalam ayat jilbäb. Sebagian mereka ada yang menafsirkan dengan menutup wajah dan kepala serta hanya menampakkan satu mata, dan sebagian mereka ada yang menafsirkan dengan menutup muka mereka. ${ }^{16}$

Menurut Al-Qurțubi, jilb $\bar{a} b$ adalah pakaian yang menutup seluruh badan. Ia juga menyebutkan bahwa menurut Syech Al-Hasan, ayat tersebut memerintah kaum wanita untuk menutup setengah wajahnya. ${ }^{17}$

Al-Zamakhsyari dalam Al-Kasysyäf merumuskan jilbāb sebagai pakaian yang lebih besar daripada kerudung, tetapi lebih kecil daripada selendang. Ia dililitkan di kepala perempuan dan membiarkannya terulur ke dadanya. ${ }^{18}$

Menurut Abu Bakar Al-Jazairi, "hendaklah mereka mengulurkan jilbabnya ke seluruh tubuh mereka" artinya mengulurkan jilbāb ke wajah mereka sehingga yang tampak dari seorang wanita hanyalah satu matanya yang digunakan untuk melihat jalan jika dia keluar untuk suatu keperluan. ${ }^{19}$

\footnotetext{
${ }^{13}$ Majma' Al-Lughah Al-Arabiyyah, Al-Mu’jam Al-Wasit, (Kairo: Dal al-Wafa, 1987), h. 133.

${ }^{14}$ Ibnu Manzur, Lisān al-'Arab, jilid, h. 272.

${ }^{15}$ Al-Hafiz Ibnu Kasir, Tafsir Al-Qur’an Al-Adzìm, jilid 3 (Cet. I; Kairo: Dāarul Hadìis, 2003), h.
} 631.

${ }^{16}$ Muhammad bin Jarir Al-Tabari, Jami'u al-Bayān fí Tafsiril Qur'ān, (Cet. I; Mekah: Muassasah Ar-Risalah, 2000), h. 324-325.

${ }^{17}$ Al-Qurthubi, al-Jami' li-Ahkam Al-Qur'an, juz XIV, (Beirut: Dār al-Kutub al-'Ilmiyah, 1993), h. 98

${ }^{18}$ Al-Zamkhsyari, Al-Kasysyāf, (Beirut: Dār al-Fikr, t.th), h. 46.

${ }^{19}$ Abu Bakar Al-Jazairi, Aisar al-Tafasir, (Beirut: Dar al-Fikr, 1977), h. 23 
Al-Tirmizì dalam Al-Mukhtasar Al-Syamāil Al-Muhammadiyyah menafsirkan mengulurkan jilb $\bar{a} b$ dengan menutup seluruh tubuh, kecuali satu mata yang digunakan untuk melihat. Di antara yang memaknainya demikian ialah Ibnu Mas'ud, Ibnu Abbas, Abidah As-Salmani, dan lain-lain. ${ }^{20}$

Menurut Wahbah Al-Zuhaily, ayat jilb $\bar{a} b$ menunjukkan wajibnya menutup wajah wanita. Karena para ulama dan mufassir seperti Ibnul Jauzi, At-Tabari, Ibnu Katsir, Abu Hayyan, Abu Su'ud, Al-Jassaș, dan Ar-Razi menafsirkan mengulurkan jilb $\bar{a} b$ adalah menutup wajah, badan, dan rambut dari orang-orang asing (non mahram) atau ketika keluar untuk sebuah keperluan. ${ }^{21}$

Dari rujukan di atas, dapat kita ambil kesimpulan bahwa jilbāb pada umumnya adalah pakaian yang lebar, longgar, dan menutupi seluruh bagian tubuh. Sementara itu, para ahli tafsir berbeda pendapat tentang makna "Hendaklah mereka mengulurkan jilbabnya ke seluruh tubuh mereka." Di antara tafsiran mereka terhadap ayat tersebut ialah: menutup wajah dan kepalanya, serta hanya memperlihatkan mata kirinya; menutup seluruh badan dan separuh wajah dengan memperlihatkan kedua mata; dan mengulurkan kain untuk menutup kepala hingga dada.

Untuk mengetahui hal itu, kita perlu mengaji buku-buku tafsir yang sudah diakui dan diterima oleh umat Islam di dunia. di antaranya ialah:

\section{Tafsir Ibnu Abbas}

Dalam menafsirkan ayat jilbāb tersebut, Ibnu Abbas menuturkan, "Selendang atau jilbāb tudung wanita hendaklah menutupi leher dan dada agar terpelihara dari fitnah atau terjauh dari bahaya zina. ${ }^{22}$

\section{Tafsir Al-Qurtubi}

Dalam menafsirkan ayat jilbāb tersebut, Al-Qurthubi menulis, "Allah memerintahkan segenap kaum muslimah agar menutupi seluruh tubuhnya, agar tidak memperlihatkan tubuh dan kulitnya kecuali di hadapan suaminya, karena hanya suaminya yang dapat bebas menikmati kecantikannya."23

\section{Tafsir Ibnu Kasir}

Menurut tafsir Ibnu Katsir, dalam QS. Al-Aḩzāb /33: 59 Allah memerintah Rasul-Nya agar menyuruh wanita-wanita beriman khususnya para istri dan anak beliau karena kemuliaan mereka untuk mengulurkan jilbäbnya ke seluruh tubuh mereka guna membedakan dari wanita jahiliyah dan budak. Jilb $\bar{a} b$ adalah selendang di atas kerudung. Muhammad bin Sirin berkata, "Aku bertanya kepada Abidah As-Salmani

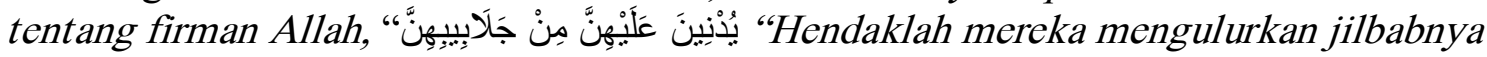
ke seluruh tubuh mereka " maka ia menutup wajah dan kepalanya, serta hanya memperlihatkan mata kirinya. ${ }^{24}$

20 At-Tirmidzi, Al-Mukhtașar Al-Syamāil Al-Muhammadiyyah, (Urdun: Al-Makatabah AlIslamiyyah, t.th). h. 349.

21 Wahbah Al-Zuhaily, At-Tafsir Al-Munir fì al-Aqīdah wa al-Syarì $a h$ wa al-Manhaj, Jilid 11 (Cet. I; Damaskus: Dār al-Fikr, 1991), h. 107.

${ }^{22}$ Ibnu Abbas, Tanwïr al-Miqbās min Tafsïr Ibn Abbās, (t.tk: t.t, t.th), h. 133

${ }^{23}$ Al-Qurțubi, al-Jami' li-Ahkàm Al-Qur'àn, juz XIV, (Beirut: Dar al-Kutub al-Ilmiyah, 1993),

h. 87

${ }^{24}$ Al-Hafiz Ibnu Kàsir, Tafsìr Al-Qur'ān Al-Aẓhïm, jilid 3 (Cet. I; Cairo: Dār al-Hạis, 2003), h. 631. 
Masri

\section{Tafsir Sayyid Qutb}

Menurut Sayyid Qutb, dalam ayat tersebut Allah memerintahkan kepada istriistri Nabi dan kaum muslimah umumnya agar setiap keluar rumah senantiasa menutupi tubuh, dari kepala sampai ke dada dengan memakai jilba $\bar{a}$ tudung yang rapat, tidak menerawang, dan juga tidak tipis. Hal demikian dimaksudkan untuk menjaga identitas mereka sebagai muslimah dan agar terpelihara dari tangan-tangan jahil dan kotor. Karena mereka yang bertangan jahil dan kotor itu, pasti akan merasa kecewa dan mengurungkan niatnya setelah melihat wanita yang berpakaian terhormat dan mulia secara islam. ${ }^{25}$

\section{Tafsir Al-Tabrasì}

Maksudnya, katakanlah kepada mereka untuk menutup dadanya dengan jilbāb, yaitu pakaian penutup yang membalut keindahan wanita. ${ }^{26}$

\section{Tafsir Wahbah Al-Zuhaily}

Maksudnya, Allah meminta Rasul-Nya memerintahkan wanita-wanita mukminat, khususnya para istri dan anak beliau, jika keluar rumah untuk menutupkan jilbăb-jilbăb mereka agar membedakannya dari para budak. Ayat ini menunjukkan wajibnya menutup wajah wanita. Karena para ulama dan mufassir seperti Ibnul Jauzi, At-Thabari, Ibnu Katsir, Abu Hayyan, Abu Su'ud, Al-Jashash, dan Ar-Razi menafsirkan mengulurkan jilbāb adalah menutup wajah, badan, dan rambut dari orangorang asing (non mahram) atau ketika keluar untuk sebuah keperluan. ${ }^{27}$

Menurut Muhammad Mutawalli Sya'rawi, para ulama sepakat bahwa seluruh tubuh wanita adalah aurat, kecuali wajah dan telapak tangannya. Abu Hanifah menambah pengecualian itu dengan kedua kaki hingga mata kaki. ${ }^{28}$

Lebih lanjut ia menjelaskan, bahwa maksud kerudung dalam ayat di atas adalah kain yang menutupi kepala. Kata dada juga meliputi leher. Dengan demikian, kerudung itu wajib menutupi kepala, leher, dan dada. Itulah batas bagian atas dari hijab. Lalu di mana batas bagian bawahnya? Jawabannya terdapat dalam bagian ayat berikutnya:

"Dan janganlah mereka memukulkan kakinya agar diketahui perhiasan yang mereka sembunyikan. Dan bertaubatlah kamu sekalian kepada Allah, hai orangorang yang beriman supaya kamu beruntung. " 29

Perhiasan kaki adalah gelang-gelang kaki. Karena para wanita menutupi tubuh mereka sampai ke kaki, maka mereka mengentakkan kaki untuk menunjukkan perhiasan yang ada di balik pakaian yang menutupi pergelangan kaki mereka. Ayat ini menunjukkan bahwa wanita harus menutupi kaki mereka sampai tumit. ${ }^{30}$

${ }^{25}$ Sayyid Qutb, Fï Zilāl al-Qur'an, (Kairo: Dar al-Wafa, t.th), h. 151.

${ }^{26}$ Abu Ali Al-Fạ̣l bin Hasan bin Fạ̣l Al-Ṭabrasi, Majma' Al-Bayān fỉ Tafsìir Al-Qur'ān, jil 8 (Cet. I; Beirut: Dar al-Kutub al-'Ilmiyyah, 1997), h.137.

${ }^{27}$ Wahbah Al-Zuhaily, Al-Tafsir Al-Munir fi al- 'Aqīdah wa al-Syarī' ah wa al-Manhäj, jilid 11 (Cet. I; Damaskus: Dar al-Fikr, 1991), h. 107.

${ }^{28}$ Muhammad Mutawalli Sya'rawi, Fiqih Wanita, (terj.) Ghozi. M, Dāri judul Fiqh al-Mar'ah al-Muslimah, (Cet. I; Jakarta: Pena Pundi Aksara, 2006), h. 50.

${ }^{29}$ Departemen Agama RI, Al-Qur'anul Karim Terjemah dan Tajwid Berwarna disertai Tafsir Ringkas Ibnu Katsir, QS. Al-Nur/24: 31, h. 548.

${ }^{30}$ Muhammad Mutawalli Sya'rawi, Fiqih Wanita, h. 51-52 
Menurut Yusuf Al-Qardhawi, di kalangan ulama sudah ada kesepakatan tentang masalah 'aurat wanita yang boleh ditampakkan'. Merujuk pada Q.S. QS. Al-Nur/ 24: 31.

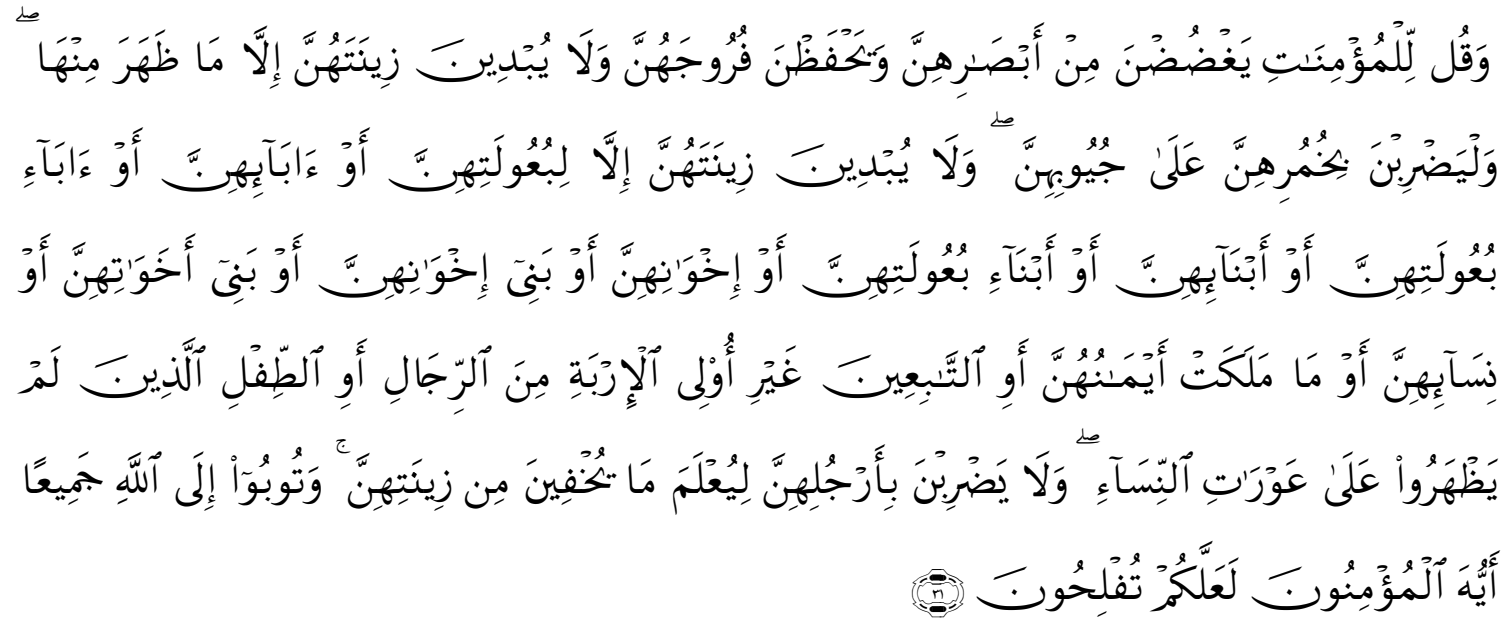

Terjemahan :

"Hendaklah mereka menahan pandangannya, dan kemaluannya, dan janganlah mereka Menampakkan perhiasannya, kecuali yang (biasa) nampak dari padanya. dan hendaklah mereka menutupkan kain kudung kedadanya, dan janganlah Menampakkan perhiasannya kecuali kepada suami mereka, atau ayah mereka, atau ayah suami mereka, atau putera-putera mereka, atau putera-putera suami mereka, atau saudara-saudara laki-laki mereka, atau putera-putera saudara lelaki mereka, atau putera-putera saudara perempuan mereka, atau wanitawanita Islam, atau budak- budak yang mereka miliki, atau pelayan-pelayan lakilaki yang tidak mempunyai keinginan (terhadap wanita) atau anak-anak yang belum mengerti tentang aurat wanita. dan janganlah mereka memukulkan kakinyua agar diketahui perhiasan yang mereka sembunyikan. dan bertaubatlah kamu sekalian kepada Allah, Hai orang-orang yang beriman supaya kamu beruntung. ${ }^{31}$

Ketika membahas makna "Dan janganlah mereka menampakkan perhiasannya kecuali apa yang biasa tampak daripadanya", menurut Qardhawi, para ulama sudah sepakat bahwa yang dimaksudkan itu adalah "muka" dan "telapak tangan". 32

Imam Al-Nawawi dalam Al-Majmü', menyatakan bahwa aurat wanita adalah seluruh tubuhnya kecuali wajah dan telapak tangannya. Di antara ulama mazhab Syafi'i ada yang berpendapat, telapak kaki bukan aurat. Imam Ahmad menyatakan, aurat wanita adalah seluruh tubuhnya kecuali wajahnya saja. ${ }^{33}$

Di antara ulama mazhab Maliki ada yang berpendapat, bahwa wanita cantik wajib menutup wajahnya, sedangkan yang tidak cantik hanya mustahab (dianjurkan). Al-Qardhawi menyatakan bahwa aurat wanita adalah seluruh tubuh kecuali wajah dan

\footnotetext{
${ }^{31}$ Departemen Agama RI, Al-Qur'anul Karim Terjemah dan Tajwid Berwarna disertai Tafsir Ringkas Ibnu Katsir, QS. Al-Nur/ 24: 31, h. 548.

${ }^{32}$ Yusuf Al-Qardhawi, Fatwa-Fatwa Kontemporer (Jakarta: GIP, 1995), h. 431-436.

${ }^{33}$ Yusuf Al-Qardhawi, Fatwa-Fatwa Kontemporer , h. 431-436.
} 
Masri

telapak tangan adalah pendapat seluruh sahabat dan tabi'in sebagaimana yang tampak jelas pada penafsiran mereka terhadap ayat, "apa yang biasa tampak dari padanya." 34

Pendapat semacam ini bukan hanya ada di kalangan Sunni. Di kalangan ulama Syi' ah juga ada kesimpulan, bahwa "apa yang biasa tampak daripadanya" ialah "wajah dan telapak tangan" dan perhiasan yang ada di bagian wajah dan telapak tangan. Murtaḍa Mutahhari menyimpulkan, “... dari sini cukup jelas bahwa menutup wajah dan dua telapak tangan tidaklah wajib bagi wanita, bahkan tidak ada larangan untuk menampakkan perhiasan yang terdapat pada wajah dan dua telapak tangan yang memang sudah biasa dikenal, seperti celak dan kutek yang tidak pernah lepas dari wanita." 35

Bahkan, dalam Wawasan Al-Quran, M. Quraish Shihab sendiri sudah mengungkapkan, bahwa para ulama besar, seperti Said bin Jubair, Atha, dan AlAuza'iy berpendapat bahwa yang boleh dilihat hanya wajah wanita, kedua telapak tangan, dan busana yang dipakainya. ${ }^{36}$

${ }^{34}$ Yusuf Al-Qardhawi, Fatwa-Fatwa Kontemporer, h. 431-436.

${ }^{35}$ Murtadha Muthahhari, Wanita dan Hijab (Jakarta: Lentera Basritama, 2002) dikutip Dāri Catatan Akhir Pekan (CAP) Adian Husaini, http://www.hidayatullah.com. (13 Oktober 2014).

${ }^{36}$ Quraish Shihab, Wawasan Al Qur'an, (Bandung: Mizan, 2000), h. 175-176. 


\section{PENUTUP}

\section{a. Kesimpulan}

1. Perintah menutup aurat (satr al-'aurah) itu sesungguhnya berbarengan dengan perintah menjaga pandangan (ghadd al-bashar) dan memelihara kehormatan (hifz al-furuj). 3 in 1 ini sering dilupakan oleh para penggugat jilbăb. Bagaimana mungkin di Bali kita dapat meminimalisir menjaga pandangan (ghadd al-bashar) jika menutup aurat (satr al-'aurah) itu tidak dilakukan? Sehingga di Bali, fenomena tidak menjaga kehormatan (hifz alfuruj) sulit terjadi. Pegaulan bebas pun meledak. Penyakit sosial (broken home, narkotika, protistusi, asusila) dan dan penyakit medis (HIV / AIDS, sepilis raja singa, kutil) bermunculan. Na' 'ंżu billah. Wallăhu a'lam.

2. Menutup aurat dalam Islam kewajiban bagi mereka yang telah dewasa (bāligh-mumayyiz). Dasar kewajiban menutup aurat adalah bersumber dari al-Qur'an dan Sunnah. Kemudian diramu oleh para ulama hingga menghasilkan fikih aurat yang merupakan bagian dari pada fikih wanita.

\section{b. Implikasi}

1. Mengenakan jibab hendaklah sesuai dengan ajaran al-Qur'an dan sunnah. Fenomena jilboobs, jilb $\bar{a} b$ telanjang, jilb $\bar{a} b$ gaul, jilb $\bar{a} b$ Ramadhan, dan jilb $\bar{a} b$ artis adalah kesalahan dalam berpakaian. Sebaiknya diubah. Jilbāb bukan persoalan kesadaran, melainkan persoalan kewajiban (taklif) bagi wanita muslimah. Apakah yang belum mengenakan jilba $\bar{a}$ itu belum sadar (baca: tobat)?

2. Jilbab bukan lambang kesucian, melainkan lambang keshalehan. Orang yang berjilb $\bar{a} b$ memang bukanlah orang suci total, melainkan berupaya menaati perintah agama sehingga meraih kesucian lahir dan batin dan mendapat ganjaran pahala dari tuhan serta meminimalisir pengaruh buruk seperti gangguan orang jahat dan gangguan mata. 
Masri

\section{DAFTAR PUSTAKA}

Azhar Basyir, Ahmad. Refleksi atas Persoalan Keimanan (Seputar Masalah Filsafat, Hukum, Politik dan Ekonomi), Bandung: Mizan, 1996.

Al-Qurthubi, al-Jami' li-Aḥkām Al-Qur'an, juz XIV, Beirut: Dār al-Kutub al-'Ilmiyah, 1993.

Al-Zamkhsyari, Al-Kasysyäf, Beirut: Dār al-Fikr, t.th.

Abu Bakar Al-Jazairi, Aisar al-Tafāsir, Beirut: Dār al-Fikr, 1977.

Al-MukhtasarAl-Syamäil Al-Muhammadiyyah, At-Tirmidzi. (Urdun: Al-Makatabah Al-Islamiyyah, t.th).

Abu Ali Al-Faḍl bin Hasan bin Faḍl Al-Tabrasi, Majma' Al-Bayān fí Tafsìir Al-Qur'an, jil 8. Cet. I; Beirut: Dar al-Kutub al-'Ilmiyyah, 1997.

Al-Qardhawi, Yusuf . Fatwa-Fatwa Kontemporer, Jakarta: GIP, 1995.Qadir, Zuly. Islam Liberal: Varian-Varian Liberalisme Islam di Indonesia 1991-2002. Yogyakarta: LkiS, 2002.

Al-Khatīb Al-Syarbinī, Muhammad. Mughnī al-Muhtaj, Juz I, Mesir: Mathba'ah alIstiqamah, $1374 \mathrm{H} / 1955 \mathrm{M}$.

Husin Al Munawar, Said Agil. Al-Quran: Membangun Tradisi Keshalehan Hakiki. Jakarta: Ciputat Press, 2003.

Ibnu Kàīir, Al-Hafiz. Tafsir Al-Qur'an Al-Adzïm, jilid 3. Cet. I; Kairo: Dārul Hadìis, 2003.

Makram Ibn Manzụur, al-Din Muhammad Ibn, Abu al-Fadl Jamal. Lisān al-'Arab, jilid 4 , Beirut: Dar Sad, t.th.

Majma’ Al-Lughah Al-Arabiyyah, Al-Mu'jam Al-Wasit, Kairo: Dal al-Wafa, 1987.

Mandzur, Ibnu. Lisān al- 'Arab, jilid 1 Cet I; Beirut: Dār Shadir, 1976.

Mutawalli Sya'rawi, Muhammad. Fiqih Wanita, (terj.) Ghozi. M, dari judul Fiqh alMar'ah al-Muslimah, Jakarta: Pena Pundi Aksara, 2006.

Muthahhari, urtadha. Wanita dan Hijab (Jakarta: Lentera Basritama, 2002) dikutip Dari Catatan Akhir Pekan (CAP) Adian Husaini, http://www.hidayatullah.com. (13 Oktober 2014).

Shihab,Umar. Kontektualitas Al-Quran: Kajian Tematik Atas Ayat-Ayat Hukum Dalam Al Qur'an. Jakarta: Penamadani, 2005.

Syihāab al-Dīn Ahmad bin Aḥmad bịn Salamah Qalyūbi dan Syihāab al-Dīn Ahmad alBarlasì Ümairah, Hasyiyàtani Qalyūbi wa Amïrah, jilid III Beirut: Dar al-Fikr, 1995.

Tim Penyusun Kamus Pusat Pembinaan dan Pengembangan Bahasa Departemen Pendidikan dan Kebudayaan, Kamus Besar Bahasa Indonesia.

Jarir Al-Tabari, Muhammad bin. Jami’u al-Bayān fí Tafsìiril Qur'ān, Cet. I; Mekah: Muassasah Ar-Risalah, 2000.

Wahbah Al-Zuhaily, At-Tafsir Al-Munïr fí al-Aqīdah wa al-Syarí'ah wa al-Manhaj, Jilid 11. Cet. I; Damaskus: Dar al-Fikr, 1991. 